\title{
Extradición de Rafael Correa vs asilo en Bélgica
}

Extradition of Rafael Correa vs asylum in Belgium

\section{Iván Rodrigo Ávalos Barreno}

Investigador jurídico independiente

Socio del Estudio Jurídico Montero Riofrío.

Ciudad: Quito

País: Ecuador

Articulo original (investigación)

RFJ, No. 7, 2020, pp. 158-178, ISSN 2588-0837

RESUMEN: El trabajo analiza a la figura de la extradición y el asilo, a la luz del derecho internacional, conjuntamente con la posibilidad de que estas sean aplicadas en contra o a favor del expresidente del Ecuador Rafael Correa; utilizando para ello el método teórico de deducción al partir de los principios normativos de ambas figuras para aplicarlos teóricamente en el caso de Correa. La extradición es abordada en un primer apartado para luego continuar con los requisitos que el Ecuador debe tomar en cuenta para solicitarla, a continuación se intenta dar respuesta a la pregunta $¿$ Es requisito sine qua non la existencia de un convenio internacional entre el país requirente y el país requerido para aplicar la extradición?, el siguiente apartado trata sobre el principio de no intervención, posteriormente el asilo y la posibilidad de que Correa se beneficie del mismo así como los dictámenes de ACNUR son expuestos, para por ultimo realizar un cuadro comparativo entre la extradición y el asilo. El artículo concluye en que son más los fundamentos técnicojurídicos en pos de que Correa obtenga el asilo en Bélgica, evadiendo así la extradición.

PALABRAS CLAVE: soberanía, refugio, Estado, extradición, asilo.

ABSTRACT: This paper analyzes the figure of extradition and asylum, through international law, together with the possibility that they may be applied in favor or against the former president 
of Ecuador Rafael Correa; using for this the theoretical deduction method based on the normative principles of both figures to apply then theoretically in the case of Correa. The extradition is analyzed in the first chapter and then continues with the requirements that Ecuador needs to request it, next the question $\dot{i}$ the existence of an international agreement between the requesting country and the required country to apply the extradition is a sine qua non-requirement? Is try to answer, the next chapter deals with the principle of non-intervention, subsequently, the asylum and the possibility that Correa would benefit for it and the ACNUR's opinions are exposed, for finally make a comparative table between extradition and asylum. The article concludes that there are more technicallegal foundations for Correa to obtain asylum in Belgium, thus avoiding the extradition.

KEY WORDS: sovereignty, asylum, State, an international treaty.

\section{INTRODUCCION}

Rafael Correa Delgado estuvo a la cabeza del país por diez años consecutivos, tiempo en el cual efectuó varios cambios sustanciales; cambios que afectaron a ciertos grupos sociales y beneficiaron a otros. En su trayectoria política al mando del Ecuador dividió por completo a los habitantes del país, por un lado se encuentran aquellos quienes piensan que tanto Correa como el movimiento alianza país han sido la mejor expresión de democracia y buen gobierno, mientras que en el otro costado están los que afirman haber soportado al peor gobierno de la historia.

De una u otra forma Rafael Correa a pesar de haber culminado con su periodo presidencial, sigue siendo el protagonista principal de varios noticieros a nivel nacional como internacional, sobre todo por los supuestos actos de corrupción cometidos, los cuales perjudican tanto su pasado político como el del movimiento del cual fue parte.

Los supuestos actos de corrupción efectuados bajo el 
liderato de Correa, salen a la luz en la actualidad debido a que existen serios indicios los cuales permiten tener la certeza de que en el periodo presidencial de Rafael, tanto fiscales como jueces e incluso la contraloría, formaban parte de su red de corrupción, por lo que coadyuvaban a blindar sus artimañas; motivo por el cual se han designado a nuevas autoridades.

En este sentido la nueva Fiscal General del Ecuador, Diana Salazar, a investigado tanto a Rafael Correa como a varias otras personas afines a su partido político por el delito de cohecho, investigación que ha logrado encontrar los suficientes elementos por medio de los cuales el tribunal ha encontrado a Correa culpable del delito, imponiéndole la pena privativa de libertad de 8 años. Dicha sentencia aun es recurrible, por lo tanto no causa cosa juzgada, de manera que solicitar al momento la extradición de Correa seria contrario a derecho, pero para los efectos de este análisis se supondrá que a pesar de los recursos que se presenten en contra de dicha sentencia, el fallo no cambiara y por lo tanto se solicitara la extradición de Rafael Correa.

El cumplimiento de la pena privativa de libertad en contra de Correa se vuelve difícil de concretar debido a que el expresidente actualmente reside en Bélgica, país al que decidió trasladar su residencia después de culminar con su último periodo presidencial.

En virtud de ello existen dos claras posibilidades; la primera de ellas es que Ecuador efectué la debida solicitud a la Interpol por parte de la Corte Nacional de Justicia, de manera que esta institución internacional capture al ex mandatario para así poder continuar con el trámite de su extradición al país; mientras que la segunda posibilidad es que Correa solicite asilo en Bélgica. Estas posibilidades son excluyentes una de otra.

El asilo y la extradición son instituciones propias del derecho internacional; las cuales serán delicadamente tratadas y estudiadas tanto por parte del Estado ecuatoriano así como por los asesores jurídicos de Correa en pos de aplicar una u otra. En el caso de que se aplicara la extradición el efecto inmediato que produciría es el retorno de Correa al Ecuador para que enfrente la justicia, mientras que por el contrario de aplicarse el 
asilo Correa se beneficiaria de la protección belga y evadiría el cumplimiento de la sentencia.

El ensayo en cuestión analizara en un primer capítulo la figura de la extradición a la luz del derecho internacional privado, definiendo sus características elementales, así como la posibilidad de que sea aplicada en contra de Correa; un segundo capítulo tratara sobre el asilo, sus implicaciones, características, y lo que podría pasar en el eventual caso de que Correa lo solicite a Bélgica; el tercer capítulo pondrá en una balanza al refugio en un costado y la extradición en el otro con el fin de evaluar cuál de estas posibilidades es la más viable.

\section{LA FIGURA DE LA EXTRADICIÓN}

Según Mansilla y Mejía en su estudio se afirma que, la extradición es la institución jurídica que tiene por objeto la colaboración entre los Estados para evitar que un delincuente o presunto delincuente se sustraiga a un juicio o al cumplimiento de una sentencia (citado en Mansilla, 2017).

Para Mansilla (2017), la extradición es la institución internacional implementada entre Estados gracias a la celebración de un tratado para lograr la colaboración en la entrega de un procesado o presunto delincuente, con el fin de evitar la impunidad.

García Barroso sostiene que, por extradición se entiende toda entrega que un Estado soberano efectúa a otro, previa solicitud de este último, de una persona que se encuentra en el Estado requerido, para que pueda ser juzgada, o que habiendo ya sido declarada culpable dentro del territorio del Estado requirente, se le haga cumplir la pena impuesta. (Citado en Álvarez, 2015)

De estos conceptos previamente citados se puede colegir que la figura de la extradición pretende que los límites fronterizos entre diversos Estados no se conviertan en un restrictivo para que la justicia siga su curso; es decir esta figura del derecho internacional actúa cuando un presunto delincuente ha salido por diversas razones del país en el que está siendo 
investigado.

\section{Para Gómez-Robledo (2000)}

Históricamente, el derecho internacional desarrollo la institución de la "extradición" principalmente para resolver la serie de problemas que se generan cuando un presunto delincuente se refugia en un Estado que no posee jurisdicción sobre él, o ya sea que este imposibilitado para procesarlo porque los medios de prueba se encuentran fuera del país. Un Estado procede entonces a la extradición de una persona para que esta pueda ser juzgada por el país que lo requiere por supuestos delitos cometidos en contravención de su orden jurídico (p. $15)$.

El principio rector fundamental que sirve de base para que la extradición opere es principalmente la cooperación internacional ${ }^{1}$, en cuanto que los Estados que respetan su normativa interna así como la legislación internacional, se vean en la necesidad de colaborar entre sí para llegar a alcanzar la justicia.

Para poder comprender a la extradición es necesario remitirse, por lo menos de forma general, inicialmente a los elementos que conforman un Estado ${ }^{2}$; estos son: el territorio, la población, el gobierno, la soberanía y el reconocimiento internacional. A efectos del trabajo propuesto se hará referencia a los dos últimos elementos.

La soberanía como elemento componente del Estado hace referencia a aquel poder, el cual faculta a su titular para que pueda tomar decisiones de manera independiente, sin que influyan factores externos ajenos a su voluntad, con la posibilidad de que de manera unilateral logre imponer su resolución; "es así que el primer atributo de la soberanía es la

1 La colaboración internacional en el tema que nos ocupa supone el apoyo entre diversos Estados para que el derecho logre llegar a su fin principal que es la consecución de la justicia.

2 Se habla de manera muy escueta de los elementos que conforman el Estado debido a que así se va a comprender de mejor manera a la extradición, sobre todo con la delimitación del elemento soberanía. 
supremacía del poder" (Aguilar, 2014, p. 69). Esta soberanía evidentemente no es ilimitada, tiene que apegarse a los límites que le son impuestos por el derecho.

\section{Para Brey y Lozano (2017)}

El soberano es el que tiene el poder para decidir sobre la Constitución. Se mantiene, por tanto, la idea originaria de que el titular de la soberanía detenta el poder supremo del Estado, pero este poder no actúa ya de una manera absoluta o sin límites, precisamente porque lo que se pretende es que el poder del Estado se someta al Derecho (p.18).

Una vez que todos los elementos constitutivos del Estado se fusionan es necesario que haga su aparición el último de los elementos, este es el reconocimiento internacional ${ }^{3}$ el cual conlleva a que los diversos Estados alrededor del mundo tengan la certeza de que deben respetar las decisiones y reconocer como tal a un Estado.

Ambos elementos descritos de manera escueta se relacionan con el derecho internacional privado, y sobre todo con la posible extradición de Rafael Correa en cuanto que mediante la soberanía Ecuador ha decidido dictar prisión preventiva en su contra, sin que sea de relevancia la opinión de los demás países, incluso el país belga en donde reside en la actualidad el expresidente; mientras que mediante el elemento de reconocimiento internacional es necesario que Bélgica acepte como válida esta decisión.

Los efectos inmediatos que produce la extradición, una vez que sea debidamente solicitado por el país requirente, son principalmente:

-Brindar eficacia al derecho penal, coadyuvando a que se continúe con el proceso establecido por el país requirente

3 Varios son los autores quienes escriben sobre los elementos del Estado, quienes si consideran al reconocimiento internacional como elemento conformante del Estado, esto debido a que un Estado puede reunir todos los elementos necesarios pero si no los demás Estados no lo reconocen o no lo consideran como tal no podría en realidad ser un Estado. 
-Eliminar los límites fronterizos como un impedimento que obstaculiza el alcance de la justicia - Garantiza la seguridad jurídica.

\subsection{Requisitos que debe tomar en cuenta el ecuador para solicitar la extradición}

Después de un acercamiento general a lo que es la extradición es momento de analizar los requisitos que el país debe tomar en cuenta para hacer una solicitud formal en pos de solicitarla; analizando paralelamente si tales requisitos son cumplidos en el caso Rafael Correa Delgado. Estos requisitos son:

-La conducta por la cual ha sido sentenciada la persona sujeto de la extradición, o la conducta por la cual está siendo procesada, debe estar tipificada tanto en la legislación interna del país requirente así como en la legislación del país requerido.

Son varios los delitos por los cuales el expresidente Correa está siendo investigado, entre ellos el tráfico de influencias, y se ha obtenido ya una sentencia condenatoria en su contra por el delito de cohecho, delitos cuya conducta está tipificada en el Código Orgánico Integral Penal del Ecuador. En el país Belga son también consideradas delito estas conductas, por lo cual el primer requisito estaría siendo cumplido.

-Es obligatorio que el Estado requirente demuestre motivada y justificadamente la causa por la cual está siendo procesado el sujeto, es decir exponga la existencia de una sentencia condenatoria en su contra, o la solicitud de prisión preventiva a luz de su legislación interna.

Recordemos que mientras la fiscalía realizaba su investigación, en el proceso por el cual actualmente Correa ha recibido una sentencia condenatoria, se creyó asistida de los suficientes elementos de convicción de manera que solicito la prisión preventiva para Rafael Correa, por lo tanto creemos que en este punto del trabajo es procedente tratar el tema. 
Para que proceda la prisión preventiva como medida cautelar en el Ecuador, es necesario cumplir con los parámetros expuestos en el artículo 534 del COIP; los 2 primeros numerales de dicho articulado se refieren a la exposición de elementos de convicción, presentados por el fiscal hacia el juez, los cuales demuestren la existencia de un delito y la participación del procesado en el mismo; requisitos que fueron cumplidos de tal manera que el tribunal de la Corte Nacional de Justicia acepto dicha medida cautelar.

El tercer numeral del artículo 534 del COIP establece que deben existir "indicios de los cuales se desprenda que las medidas cautelares no privativas de libertad son insuficientes...". (Código Orgánico Integral Penal, 2014, art.534 num.4). Debido a que el expresidente se encuentra fuera del país y sus posibilidades económicas son suficientes como para continuar con su residencia en Bélgica o incluso trasladarse a otro Estado, es necesario que la prisión preventiva sea aplicada, tomando en consideración que el procesado comparezca al proceso y cumpla la pena; por estas razones este requisito del numeral tercero se habría cumplido.

Los supuestos delitos cometidos por Correa según el COIP prevén una pena privativa de libertad de 1 a 3 años para el cohecho, de 3 a 5 años para la asociación ilícita y de 3 a 5 años también para el tráfico de influencias; lo cual se relaciona con el artículo 534 del mencionado cuerpo legal que establece los requisitos para que proceda la prisión preventiva, “...que se trate de una infracción sancionada con pena privativa de libertad superior a un año". (Código Orgánico Integral Penal, 2014, art. 534 num. 4). Razón por la cual este requisito también estaría siendo cumplido.

A más de que, como se acaba de señalar, los requisitos en cuanto a la prisión preventiva serian cumplidos por el Estado ecuatoriano (cosa que actualmente deja de ser relevante en razón de que ya existe una sentencia condenatoria), la existencia de una sentencia también es ya una realidad, a pesar de que como ya se mencionó anteriormente dicha sentencia es recurrible.

-Es necesario que el Estado requirente tenga jurisdicción 
para poder juzgar y ejecutar lo juzgado.

Con respecto este requisito es claro que los jueces de la Corte Nacional de Justicia tienen plena jurisdicción en materia penal, al ejercer su cargo de acuerdo al nombramiento legal pertinente. De igual forma los delitos supuestamente cometidos por Rafael Correa fueron ejecutados dentro del territorio nacional, razón por la cual su conocimiento corresponde a los jueces ecuatorianos. Este requisito estaría cumplido.

-Como último requisito se estipula la necesidad de que exista un convenio internacional de extradición entre el país requirente y el país requerido

\subsection{1 ¿Es requisito sine qua non la existencia de un convenio internacional para aplicar extradición?}

Este último especial requisito de la existencia de un convenio, el cual "es un compromiso internacional adquirido por los Estados" (Icaza y Lara, 2017, p.77) merece cierto análisis más amplio a diferencia de los demás requisitos previamente estipulados, debido a que surge un problema ya que existe una dicotomía en la doctrina. Varios son los expertos quienes aseguran que es necesario un convenio internacional entre el país requirente y el país requerido para que tenga lugar la extradición, mientras que otros tratadistas del derecho internacional aseguran que este convenio no es indispensable.

Según Pérez (2009), procede la petición de extradición únicamente cuando así lo determinan los tratados (ya sean bilaterales o multilaterales) existentes entre ambos países que forman parte de la extradición. Mientras que para Akehurst no existe en derecho positivo ninguna obligación de llevar a cabo la extradición a falta de un tratado. Sin embargo, un Estado puede llevar a cabo actos de extradición, sin que medie un tratado, es decir, no existe tampoco una norma internacional que prohíba a los Estados ejecutar extradiciones en ausencia de acuerdos formales. (Citado en Gómez-Robledo, 2000).

Los tratados internacionales son acuerdos celebrados entre dos o más Estados, o entre un Estado y una Organización Internacional, con el fin de asistirse mutuamente en cualquier 
ámbito de relevancia para ambos; debe ceñirse a ciertas solemnidades sustanciales y está reglamentado por el derecho internacional ${ }^{4}$.

En el caso de que si existiese un tratado o convenio internacional sobre extradición su procedimiento se tornaría mucho más ágil entre los países interesados; pero ¿Qué es lo que sucede cuando no existe un convenio internacional al respecto?

Para poder contestar la pregunta previamente planteada es necesario hacer remisión a uno de los principios fundamentales y básicos del derecho internacional en materia de extradición; este principio según Cañardo (2013) es el llamado aut dedere aut punire, lo que se traduce en o bien se castiga al sospechoso o bien se lo entrega para que sea castigado ${ }^{5}$. En este sentido el país requerido en caso de no entregar al sospechoso debería castigarlo a la luz de su propia legislación; cosa que es muy difícil ya que en ese país seguramente no se contara con las pruebas suficientes que permitan tener la certeza de que el sospecho cometió un delito ya que lo materializo en otro Estado, es por ello que lo mejor es entregarlo al país requirente.

Con el fin de entregar al sospechoso a pesar de la inexistencia de un tratado internacional entre los países interesados, es necesario que el país requerido observe otro de los principios del derecho internacional como es la cooperación entre Estados. Según este principio es fundamental que los países se asistan mutuamente en diversos ámbitos, inclusive en cuanto a la extradición. Es por ello que según mi personal entender no es un requisito sine qua non la existencia de un convenio internacional para la tramitación de la extradición.

De todas maneras si existe un convenio internacional entre Ecuador y Bélgica que abarca el tema de la extradición; este fue suscrito en 1887 y contempla la posibilidad de que se

4 Los tratados internacionales están reglamentados por el Derecho Internacional, pero también lo están por el Derecho Interno, esto en cuanto, específicamente en el caso de nuestro país, la Constitución establece la forma en que los Tratados Internacional serán ratificados para que rijan en el país.

5 Lo que busca el principio aut dedere aut punire es que las personas quienes han violentado la ley, o se sospecha que lo han hecho, sean ajusticiadas sin que los límites fronterizos se conviertan en barreras para que ello suceda. 
extradite a un delincuente o presunto delincuente por varios delitos. Debido a la antigüedad del documento los delitos que en este se estipulan no responden a la actualidad social de ambos países, cosa que complicaría una posible extradición de Correa; pero como se acaba de afirmar en líneas precedentes un tratado internacional no es requisito indispensable en pos de esta figura del derecho internacional.

\subsection{El principio de derecho internacional non inquiry o no intervención vs consideraciones del país requerido para aceptar la extradición.}

Como ya se expuso anteriormente los requisitos a la luz del derecho internacional que son de necesario cumplimiento para que proceda la extradición en contra de Correa son cumplidos por el Estado ecuatoriano; pero según Cañardo (2013) la extradición puede no ser atendida por el país requerido cuando la persona a ser extraditada corra el peligro de sufrir un trato injusto o inhumano, debido sobre todo a que el sistema judicial del país requirente es corrupto o está motivado por la venganza.

En los últimos meses el Ecuador ha sido visto internacionalmente por medio de los diversos noticieros y otros medios de comunicación masiva como el internet, como un país con varios problemas de corrupción ${ }^{6}$; basta con recordar el reciente inconveniente que envolvió a gran parte de América Latina como fue la trama de sobornos de Odebretch, el famoso caso en el 2007 de los conocidos "Pativideos" en donde el ex ministro Ricardo Patiño aparecía maniatando la economía nacional, en el 2014 nuevamente Ricardo Patiño como canciller dejaba por los suelos al Ecuador a ojos del conglomerado internacional ya que en Italia se encontró un cargamento de droga en su valija diplomática; en el 2012 el Presidente del Banco Central admitía haber falsificado su título de economista y luego salió del país pare evitar dar cuentas a la justicia.

6 Inclusive la corrupción en el Ecuador no ha cesado a pesar de que el mundo entero lucha contra la pandemia del "coronavirus". Paul Granda delegado por el ejecutivo como titular del Consejo Directivo del IESS renunció a causa de los escándalos por sobre precio en la compra de varios artículos para enfrentar la grave situación de salud. 
Son innumerables los casos como los previamente descritos los cuales ratifican que el Ecuador tiene serios problemas de corrupción, esto sobre todo debido a que la justicia parece no llegar, o en el mejor de los casos ser efímera para aquellos que violentan la ley de manera desvergonzada a vista y paciencia de los ciudadanos que poco o nada pueden hacer al respecto. La justicia actúa de tal manera que los implicados en inconvenientes legales, después de esquivar su castigo mediante la influencia de los amañados jueces y fiscales, vuelven a ocupar altos cargos en el Ecuador.

Por razones como las estipuladas tanto Bélgica como otros países alrededor del mundo, no estarían faltando a la verdad en el caso de considerar que el sistema judicial ecuatoriano es corrupto; además es claro evidenciar que el actual Presidente Lenin Moreno, así como sus aliados quienes anteriormente formaban un solo equipo con Rafael Correa, tienen una opinión que difiere en el tiempo, esto porque anteriormente afirmaban que Correa era un gran mandatario de manos limpias y que luchaba contra la corrupción, mientras que en la actualidad aseveran que Correa en su gobierno cometía un gran número de delitos ${ }^{7}$. Estas razones son suficientes para que el país belga niegue la extradición del expresidente Rafael Correa, asumiendo que el sistema judicial en el Ecuador no solamente es corrupto, sino que también es posible que este motivado por la búsqueda de la venganza en contra de Correa por parte de los actuales mandantes del país.

Frente a estas consideraciones que podría hacer Bélgica y así negar la extradición de Rafael Correa, se encuentra un principio de derecho internacional muy conocido, este es el principio non inquiry o de no intervención en los asuntos internos. Para poder esclarecer el significado de este principio es necesario dilucidar lo que se debe entender por intervención, según el tratadista Antonio Remiro Brotóns la intervención es el acto por el que un Estado se entromete mediante la autoridad en los asuntos que son de jurisdicción domestica de otro, imponiéndole un comportamiento determinado. (Citado en

$7 \quad$ Inclusive hoy Lenin Moreno en innumerables ocasiones señala a Rafael Correa como el máximo responsable de la crisis económica que enfrenta el país. 
Bernal, 2010)

En este sentido el principio de no intervención supondría que ningún Estado puede tomarse la atribución de incidir directa o indirectamente en las decisiones de otro; esto debido a la soberanía y reconocimiento internacional como elementos esenciales en la conformación de un Estado, elementos a los que se hizo referencia en el capítulo inicial del presente trabajo. Este principio es de tal relevancia que ha sido consagrado en La Carta de Naciones Unidas (1945): "Ninguna disposición de esta Carta autorizara a las Naciones Unidas a intervenir en los asuntos que son esencialmente de la jurisdicción interna de los Estados (...)”. (art. 2 num. 7)

De esta manera encontramos nuevamente una dicotomía, por un lado, el principio de no intervención el cual en caso de ser aplicado facilitaría la extradición de Correa ya que Bélgica no estaría facultado para hacer ningún tipo de juicio de valor ni consideración acerca de la forma en la que se desarrolla la justicia ecuatoriana, mientras que por otro el posible dictamen belga que no entregaría a Correa aduciendo que la justicia ecuatoriana es corrupta y únicamente busca la venganza en su contra.

Para poder esclarecer esta discordancia doctrinaria es necesario nuevamente utilizar un principio del derecho internacional, este es la cooperación entre Estados. Aplicando este fundamental principio Bélgica debería aceptar la extradición de Correa, tomando en cuenta que es posible que en algún momento el Estado ecuatoriano se convierta en el país requerido de una extracción cambiando así los roles.

Para Raúl Gutiérrez (2017)

Asimismo, se considera necesario que la cooperación internacional no debe entenderse como un sinónimo de intromisión a la soberanía internacional por parte de los Estados, sino como los ejercicios de colaboración regidos por el principio de "buena fe" entre los mismos, a efecto de garantizar un concierto internacional cuya piedra angular sea siempre y en todo momento la defensa y protección de los derechos humanos. (p. 107) 


\section{LA FIGURA DEL ASILO}

Como Diez de Velasco afirmo en su estudio, puede decirse que el asilo es una protección que un Estado ofrece a personas que no son sus nacionales ya que su libertad o su vida corren peligro, debido a persecuciones o amenazas de otro Estado (Citado en Arlettaz, 2016).

\section{Para Ricardo Arredondo (2017)}

El asilo territorial se refiere a la potestad de todo Estado, en el ejercicio de su soberanía, de admitir dentro de su territorio a las personas que juzgue conveniente, sin que por ello ningún otro Estado pueda hacer reclamo alguno y sin importar el modo en que la persona haya ingresado en su territorio. Consecuentemente, no existe una obligación de entregar a otro Estado o a expulsar de su territorio a personas perseguidas por motivos o delitos políticos y no procede la extradición (p. 120).

El asilo en el derecho internacional es una especie de amparo ofrecido por un Estado en beneficio de una persona de cualquier nacionalidad diferente a la del Estado protector, la cual busca brindar auxilio a la persona que huye de un país en donde peligra su integridad o su vida, de manera que se le brinde resguardo y asistencia.

Tal es la relevancia del asilo en la esfera de la ciencia jurídica que ha sido consagrada en la Declaración Universal de Derechos Humanos (1948): "En caso de persecución, toda persona tiene derecho a buscar asilo, y a disfrutar de él, en cualquier país". (art.14 num.1) Cabe resaltar que dicha Declaración hace sobresalir el hecho de que el asilo puede ser disfrutado en el caso de ser perseguido.

Haciendo uso de la soberanía los países tienen la plena facultad de tomar la decisión de considerar como asilada a una persona, o por el contrario no tomarla en cuenta como tal rechazando su solicitud, sin que tengan la obligación de motivar su decisión.

Existen dos clases fundamentales de asilo ${ }^{8}$, el asilo

8 Algunos tratadistas encuentran más tipos de asilo, e incluso hacen una diferenciación conceptual entre asilo diplomático y asilo territorial, 
territorial el cual es concedido a la persona interesada, después de analizar su solicitud, en el territorio del país protector; y el asilo diplomático que es otorgado en una de las embajadas del país protector. El efecto inmediato que produce otorgar el asilo a una persona es la aceptación tácita de no extraditarla.

\subsection{ACNUR y sus dictámenes en pos del asilo}

A diferencia de la extradición la figura del asilo no contempla requisitos universales y fundamentales los cuales tengan que ser necesariamente cumplidos por la persona solicitante, el país receptor es el que impondrá soberanamente si la acepta o no, pero esto no quiere decir que no existan ciertas consideraciones a tomar en cuenta en favor de aceptar o no dicha figura de derecho internacional.

Al respecto Bélgica al igual que varios otros países alrededor del mundo es parte de la Organización de las Naciones Unidas ONU, organización internacional que tiene como objetivos primordiales la cooperación entre Estados, fomentar la paz y seguridad, y promover la correcta aplicación de los Derechos Humanos. Esta organización para su correcto funcionamiento ha creado diversas agencias o sub organizaciones las cuales tiene sus propias metas; una de estas agencias es el Alto Comisionado de las Naciones Unidas para los Refugiados ACNUR, la cual busca el bienestar de aquellas personas que se han visto en la innegable necesidad de huir de un país dándoles la posibilidad de solicitar asilo.

ACNUR realiza varias reuniones conocidas como mesa redonda, en donde mediante la intervención de expertos en el tema a tratar, determina ejes fundamentales y bases que deben ser observadas por los Estados que forman parte de esta organización. En este sentido en el año 2001 en la ciudad de Ginebra se convocó a una mesa redonda en donde se estipularon ciertas circunstancias las cuales coadyuvarían a que se otorgue el refugio a una persona, estos principalmente son:

- Los Derechos Humanos le corresponden a cada una de las personas por el simple hecho de ser humanos, le son

cosa que no será considerada en el presente artículo ya que no es tema fundamental del mismo. 
naturalmente inherentes y de pertenencia universal sin que medie discriminación alguna

- El derecho a la unidad familiar debe ser garantizado como un Derecho Humano; derecho que será tomado muy en cuenta para conceder el asilo

- La aplicación del derecho a la unidad familiar no queda condicionada a un tratado internacional, es decir no existe la necesidad de que un Estado este suscrito a un convenio que hable sobre este tema para que lo aplique.

- Para que un Estado aplique eficiente el derecho a la unidad familiar debe, de ser el caso, tomar las medidas necesarias las cuales garanticen que los miembros de la familia no van a tener que separarse; o abstenerse de ejecutar cualquier acción que desencadene en la desunión familiar.

- No existe un concepto único de familia a la luz del derecho internacional, los países están en la obligación de considerar a la familia en forma flexible, tomando en cuenta cada caso particular así como también las diferentes situaciones económicas, culturales, educativas, etc.

- En el caso de que una persona solicite asilo en un Estado las autoridades competentes están en la obligación de agilizar lo más posible el trámite y solventar la situación jurídica de la persona, sobre todo cuando existan menores de edad que se puedan ver afectados por la falta de aplicación del derecho de la unidad familiar.

Estas estipulaciones brevemente resumidas realizadas por ACNUR son las más relevantes, las cuales deberían ser tomadas en cuenta por los países en los que se solicita asilo.

\section{2. ¿Podría Rafael Correa solicitar asilo en Bélgica?}

Debido a la difícil situación jurídica y política que afronta el expresidente Rafael Correa Delgado es muy probable 
que su equipo de asesoría legal tenga la idea de solicitar asilo en Bélgica; a continuación se expondrá lo que sucedería en el hipotético caso de que su solicitud esté en manos del país europeo en el que actualmente reside.

Después de que Correa culminara con su último periodo presidencial tomo la decisión de trasladarse conjuntamente con su familia a Bélgica, país de nacionalidad de su esposa. En este Estado europeo al igual que en nuestra legislación se ha adoptado los conceptos del ius solis y ius sanguinis para poder establecer el vínculo jurídico entre una persona natural y el país, es decir tanto las personas que nacen dentro del territorio así como quienes son descendientes de un ciudadano de Bélgica son considerados sus nacionales.

En este sentido los 3 hijos del expresidente, acogiéndose el ius sanguinis, tienen la nacionalidad del país en donde se encuentra su domicilio actualmente, es decir Bélgica. Cabe resaltar que el hijo menor de la familia Correa Malherbe aún es menor de edad.

Bajo estas consideraciones en el supuesto de que Correa inicie la solicitud de asilo en Bélgica, este Estado estaría en la obligación de agilitar lo más posible el trámite (según lo decretado por la ACNUR y expuesto en líneas precedentes), tomando en cuenta que en su núcleo familiar existe un menor de edad, así como también se tendría necesariamente que tomar medidas que garanticen la unión familiar, ya que en el caso de que no se acepte el asilo y por el contrario se lo extradite se estaría propiciando a que su familia se separe.

Estas consideraciones y el hecho de que la familia de Correa ostente la nacionalidad Belga son fundamentos contundentes, los cuales inclinarían la balanza en beneficio de que Bélgica acepte el asilo en favor del expresidente, dotándole de esta forma de protección y respaldo.

\section{EXTRADICIÓN VS ASILO}

Un vez que se han expuesto, a la largo del trabajo en cuestión, los diferentes fundamentos jurídicos que apoyan 
la aplicación tanto del asilo así como de la extradición, a continuación se muestra un cuadro comparativo en donde se podrá evidenciar de mejor manera cuál de estas opciones es la más viable en el especial caso del expresidente Rafael Correa.

\begin{tabular}{|l|l|l|}
\hline Extradición & $\begin{array}{l}\text { Consideraciones que } \\
\text { permiten su aplicación en } \\
\text { el caso Rafael Correa }\end{array}$ & $\begin{array}{l}\text { Consideraciones } \\
\text { que imposibilitan } \\
\text { su aplicación en } \\
\text { el caso Rafael } \\
\text { Correa }\end{array}$ \\
\hline $\begin{array}{l}\text { Existe la petición de } \\
\text { prisión preventiva en } \\
\text { su contra } \\
\text { Hay un convenio } \\
\text { sobre extradición } \\
\text { entre Bélgica y } \\
\text { Ecuador } \\
\text { Los delitos por los } \\
\text { que se investiga a } \\
\text { Correa también están } \\
\text { tipificados en Bélgica }\end{array}$ & $\begin{array}{l}\text { - Bélgica puede } \\
\text { que la justicia } \\
\text { ecuatoriana es } \\
\text { corrupta y solo } \\
\text { busca la venganza } \\
\text { en contra de } \\
\text { Correa }\end{array}$ \\
\hline $\begin{array}{l}\text { La familia de Correa } \\
\text { tiene la nacionalidad } \\
\text { belga }\end{array}$ & $\begin{array}{l}\text { Existe un menor de } \\
\text { edad dentro de su } \\
\text { familia } \\
\text { Bélgica podría } \\
\text { considerar a Correa }\end{array}$ & $\begin{array}{l}\text { La orden } \\
\text { de prisión } \\
\text { preventiva por } \\
\text { la supuesta } \\
\text { participación } \\
\text { de Correa en } \\
\text { varios delitos } \\
\text { podría truncar la } \\
\text { político perseguido } \\
\text { solicitud de asilo } \\
\text { en Bélgica. }\end{array}$ \\
\hline
\end{tabular}

\section{CONCLUSIONES}

El principio de derecho internacional conocido como cooperación entre Estados hace posible que la existencia de un tratado internacional entre el país requirente y el país requerido deje ser un requisito sine qua non para aplicar la extradición, de todas maneras el Ecuador si cuenta con un convenio firmado 
con Bélgica el cual facilitaría la extradición de Rafael Correa.

El Ecuador cumple con los requisitos expuestos por la doctrina del derecho internacional en pos de aplicar la extradición en contra del expresidente Rafael Correa Delgado, pero a pesar de esta ventaja la extradición puede verse truncada en razón de que Bélgica tendría la posibilidad de hacer un juicio de valor acerca de nuestra justicia, y en caso de encontrarla corrupta y motivada por la venganza la extradición no sería aceptada por el país europeo; en contraposición a esta posible consideración de Bélgica acerca de nuestra justicia Ecuador podría hacer uso del principio non inquiry el cual dispone que un Estado no puede entrometerse en los asuntos propios de otro.

Si Bélgica llega a negar la extradición del expresidente debido a considerar que el sistema de justicia en el Ecuador no es del todo fiable, estaría actuando dentro de las facultades que le son atribuidas por uno de los elementos conformantes del Estado como es la soberanía, de manera que tomaría una decisión independiente sin que influya o sea de relevancia la opinión de los demás Estados alrededor del mundo, incluyendo el Ecuador.

Por el contrario si Rafael Correa solicita asilo en Bélgica para de esta manera beneficiarse de su protección y así evitar enfrentar la justicia ecuatoriana, estaría revestido de ventajas que le permitirían ganar el beneplácito belga. La ACNUR estipula que los Estados deben garantizar todas las medidas necesarias para evitar la desunión o fraccionamiento familiar, de tal manera que Correa al contar con su esposa e hijos de nacionalidad belga se vería favorecido por esta consideración, de igual manera el hecho de que cuente con menores de edad dentro de su familia constituiría otra gran ventaja en pos de que su solicitud de asilo sea aceptada.

\section{REFERENCIAS BIBLIOGRAFICAS}

Aguilar, L. (2014). Teoría General del Estado. México: Grupo Editorial Patria. 
Álvarez, C. (2015). La Asistencia Penal Internacional y la Extradición en los Delitos de Narcotráfico, Lavado de Activos y Financiamiento del Terrorismo y Corrupción Internacional. Revista de derecho y ciencias sociales, 9(10), (pp. 48-82).

Arlettaz, F. (2016). Naturaleza y alcance del asilo en el sistema interamericano de Derechos Humanos. Recuperado de: https://scielo.conicyt.cl/scielo.php?script=sci_ arttext\&pid=S0718-00122016000100007.

Arredonde, R. (2017). Wikileaks, Assange y el Futuro del Asilo Diplomático. Revista Española de Derecho Internacional, 69(2), (pp. 1119-144).

Asamblea Nacional del Ecuador. Código Orgánico Integral Penal. [Cod.] R. O. 180 de 10 de febrero de 2014.

Bernal, C. (2010). El principio de no intervención en el sistema interamericano enfocado a los casos de Nicaragua (197886) y de Colombia-Ecuador (2008). Recuperado de: https://www.javeriana.edu.co/biblos/tesis/ politica/ tesis364.pdf.

Brey, J. \& Lozano, A. (2017). Formas de Estado, Sentimiento Constitucional y Soberanía. Madrid: Dykinson.

Cañardo, H. (2013). La extradición, el delito político y el asilo extraterritorial a la luz de los principios del derecho internacional público. Revista de derecho, 8(1), (pp. 81115).

Gómez-Robledo, A. (2000). Extradición en derecho internacional: aspectos y tendencias relevantes. México: UNAM.

Gutiérrez, R. (2017). La cooperación internacional entorno a la protección de víctimas y testigos como mecanismo de combate a la delincuencia organizada transnacional.

IUDICIUM ,1(2), (pp. 103-119).

Icaza, G. y Lara, R. (2017). Derecho internacional público. México: Iure. 
Mansilla, M. (2017). Derecho internacional privado. México: Iure.

Pérez, M. (2009). Instrumentos de cooperación judicial penal I: la extradición y la euroorden. España: Universitat Jaume I.

Recibido: $12 / 04 / 2020$

Aprobado: 12/06/2020

Iván Rodrigo Avalos Barreno: Investigador jurídico independiente. Socio del Estudio Jurídico Montero Riofrío. Correo electrónico: ivanro41@hotmail.com

Ciudad: Quito

País: Ecuador 
